\title{
Hydrogen Sorption Properties of a Novel Refractory Ti-V-Zr-Nb-Mo High Entropy Alloy
}

\author{
Anis Bouzidi ${ }^{1}$, Laetitia Laversenne ${ }^{2}$, , Guilherme Zepon ${ }^{3}$, Gavin Vaughan ${ }^{4}$, Vivian Nassif ${ }^{2}$ \\ and Claudia Zlotea ${ }^{1, *}$
}

1 Université Paris Est Créteil, Institut de Chimie et des Matériaux Paris-Est (UMR7182), CNRS, UPEC, 2 Rue Henri Dunant, 94320 Thiais, France; anis.bouzidi@icmpe.cnrs.fr

2 University Grenoble Alpes, CNRS, Institut Néel, 38000 Grenoble, France; laetitia.laversenne@neel.cnrs.fr (L.L.); nassif@ill.fr (V.N.)

3 Federal University of São Carlos, Department of Materials Engineering (DEMa/UFSCar), Rodovia Washington Luiz, km 235, São Carlos 13565-905, São Paulo, Brazil; zepon@ufscar.br

4 ESRF-The European Synchrotron, 71, Avenue des Martyrs, CEDEX 9, 38042 Grenoble, France; vaughan@esrf.fr

* Correspondence: claudia.zlotea@icmpe.cnrs.fr or zlotea@icmpe.cnrs.fr

Citation: Bouzidi, A.; Laversenne, L.; Zepon, G.; Vaughan, G.; Nassif, V.;

Zlotea, C. Hydrogen Sorption

Properties of a Novel Refractory Ti-V-Zr-Nb-Mo High Entropy Alloy. Hydrogen 2021, 2, 399-413. https:/ / doi.org/10.3390/hydrogen2040022

Academic Editor: George

E. Marnellos

Received: 8 October 2021

Accepted: 21 October 2021

Published: 27 October 2021

Publisher's Note: MDPI stays neutral with regard to jurisdictional claims in published maps and institutional affiliations.

Copyright: (c) 2021 by the authors. Licensee MDPI, Basel, Switzerland. This article is an open access article distributed under the terms and conditions of the Creative Commons Attribution (CC BY) license (https:// creativecommons.org/licenses/by/ $4.0 /)$.

\begin{abstract}
High entropy alloys belong to a new and promising class of functional materials for solidstate hydrogen storage. In this context, a novel single-phase body centered cubic $(b c c)$ high entropy alloy $\mathrm{Ti}_{0.30} \mathrm{~V}_{0.25} \mathrm{Zr}_{0.10} \mathrm{Nb}_{0.25} \mathrm{Mo}_{0.10}$ was prepared. The physicochemical and hydrogen sorption properties have been determined by both laboratory and large-scale facilities. This alloy can quickly absorb hydrogen up to $2.0 \mathrm{H} / \mathrm{M}(2.8 \mathrm{wt}$.\%) at room temperature and forms a face centered cubic $(f c c)$ hydride, as proven by synchrotron X-ray diffraction. The Pressure-Composition Isotherm and in situ neutron diffraction during hydrogen/deuterium desorption reaction suggest that the alloy experiences a reversible single step phase transition $(b c c \leftrightarrow f c c)$. PDF analysis from X-ray total scattering data points out that the hydride phase possesses an average $f c c$ structure with random atoms distribution and small lattice distortion. Despite an initial small fading of the capacity, the alloy withstands 20 absorption/desorption cycling without phase decomposition, as demonstrated by kinetic measurements coupled with X-ray diffraction and microstructural study by SEM-EDS. Moreover, the complete hydrogen absorption occurs in less than $30 \mathrm{~s}$ at room temperature and the kinetic improves during cycling.
\end{abstract}

Keywords: high entropy alloy; hydrogen storage; synchrotron XRD; pair distribution function analysis; in situ neutron diffraction

\section{Introduction}

In recent decades, the reduction in our dependency on fossil fuels has become a necessity due to pollution and environmental issues. To lessen the use of hydrocarbons, which represents one of the main causes of pollution, scientists are searching for a new way to ensure an energy transition from fossil fuels to the use of hydrogen as an energy carrier. The reason for this focus on hydrogen is its abundance and the large amount of chemical energy per unit mass that this element can store. At standard temperature and pressure (STP) conditions pure hydrogen exists only as a low-density gas which hinters its use in practical and efficient applications. One of the most promising solution is to reversibly store hydrogen in solid-state materials forming metal hydrides. Many materials have been tested, such as intermetallic and complex hydrides [1]. Nevertheless, the application of these materials close to STP conditions is still impractical because of their low capacity, unfavorable thermodynamics, sluggish kinetics and loss of reversibility during cycling.

In this context, high entropy alloys (HEA) are a recent class of metallic materials that can be suitable for hydrogen storage. Since their first report by Yeh et al. [2] and 
Cantor et al. [3], HEAs are defined as disordered solid solutions containing five or more elements in nearly equimolar concentrations (5-35 at.\%) [4]. These solid solutions usually adopt simple structures such as body centered cubic $(b c c)$, face centered cubic $(f c c)$ or hexagonal close compact $(h c p)$. In order to predict the formation of solid solutions in this class of materials, two empirical parameters are used. First, the valence electron concentration (VEC) can affect the homogeneity and the structure of a solid solution phase. For example, $b c c$ solid solution of refractory alloys could exist for VEC $<7.6$ [5]. Second, the elements in HEAs are randomly distributed on the same crystallographic sites involving important lattice distortion that can be defined as $(\delta)$,

$$
\delta=\sqrt{\sum_{i=1}^{n} c_{i}\left(1-\frac{r_{i}}{\bar{r}}\right)^{2}}
$$

where $c_{i}, r_{i}$ presents the concentration and the radius of the element $i$ and $\bar{r}$ the average atomic radius of the composition. Empirical studies have shown that complete solid solutions are formed for $\delta<6.6 \%$ [6]. Distortions higher than this critical value may lead to the formation of multiphased alloys with intermetallic precipitations or even amorphous phases for $\delta>8 \%$ [7].

The mixing of metals forming hydrides into a HEA may result in the creation of a material with interesting hydrogen sorption properties. Moreover, the endless compositional space of HEAs leads to numerous candidates for hydrogen storage.

Elementary and conventional metal hydrides possess a maximum capacity of hydrogen absorption by $2.0 \mathrm{H}$ atoms per metal $(\mathrm{H} / \mathrm{M})$ [8]. Nevertheless, Sahlberg et al. reported in 2016 that the TiVZrNbHf single-phase $b c c$ alloy absorbs large amount of hydrogen reaching $2.5 \mathrm{H} / \mathrm{M}$ [9]. During the hydrogen absorption the alloy undergoes a phase transition from a $b c c$ lattice to a pseudo $f c c$ structure with a small tetragonal deformation [10]. This very important finding opened the field to the study of refractory HEAs for hydrogen storage with already several interesting reports [11-16]. Kunce et al. used laser engineered net shaping (LENS) to synthesize the equimolar TiZrNbMoV [17]. This composition is multiphased with $b c c$ and orthorhombic coexisting phases. The hydrogen absorption capacity of this alloy is $1.79 \mathrm{H} / \mathrm{M}(2.3 \mathrm{wt} . \%)$ and after an additional annealing the capacity drops to $1.45 \mathrm{H} / \mathrm{M}(1.8 \mathrm{wt} . \%)$. After hydrogenation, the material is also multiphased and no clear conclusion could be drawn due to the coexistence of several phases. This suggests that the research efforts should focus on single-phased alloys in order to clarify their interaction with hydrogen and the composition-structure-properties relationship.

Our recent work by Montero et al. focused on the optimization of the Ti-V-Zr- $\mathrm{Nb}$ system to obtain single-phased alloy by various synthetic methods [18]. The quaternary $\mathrm{Ti}_{0.325} \mathrm{~V}_{0.275} \mathrm{Zr}_{0.125} \mathrm{Nb}_{0.275}$ alloy is single-phased $b c c$ alloy and forms a dihydride with $f c c$ lattice with a maximum hydrogen absorption capacity of $1.8 \mathrm{H} / \mathrm{M}(2.7 \mathrm{wt} . \%)$. Following this study, we have adopted a new strategy for the investigation of HEAs for hydrogen storage. Our focus is placed on the investigation of the effect of adding $10 \%$ of a fifth element to the previous quaternary alloy upon the following formula: $\mathrm{Ti}_{0.30} \mathrm{~V}_{0.25} \mathrm{Zr}_{0.10} \mathrm{Nb}_{0.25} M_{0.10}(M=A l$, $M g, T a)$. The $\mathrm{Ti}_{0.30} \mathrm{~V}_{0.25} \mathrm{Zr}_{0.10} \mathrm{Nb}_{0.25} \mathrm{Al}_{0.10}$ composition was synthesized by arc melting and can absorb hydrogen forming a $b c t$ hydride with the capacity $1.6 \mathrm{H} / \mathrm{M}(2.6 \mathrm{wt} . \%)$ at room temperature [19]. The major improvements of $\mathrm{Al}$ addition are related to the desorption and cycling properties of the material. The temperature for hydrogen release was decreased by around $100{ }^{\circ} \mathrm{C}$ and the alloy showed superior cycling stability and higher reversible storage capacity than the quaternary counterpart. The $\mathrm{Ti}_{0.30} \mathrm{~V}_{0.25} \mathrm{Zr}_{0.10} \mathrm{Nb}_{0.25} \mathrm{Mg}_{0.10}$ alloy was prepared by high energy mechanosynthesis under inert atmosphere and undergoes a phase transition from a $b c c$ initial lattice to a $f c c$ hydride phase upon hydrogen absorption at room temperature (capacity $1.7 \mathrm{H} / \mathrm{M}, 2.7 \mathrm{wt} . \%$ ) [20]. The addition of $\mathrm{Mg}$ into the parent quaternary alloy improves the hydrogen absorption/desorption cycling properties. The $\mathrm{Ti}_{0.30} \mathrm{~V}_{0.25} \mathrm{Zr}_{0.10} \mathrm{Nb}_{0.25} \mathrm{Ta}_{0.10}$ alloy can absorb hydrogen up to $2.0 \mathrm{H} / \mathrm{M}(2.5 \mathrm{wt} . \%)$ and the desorption properties were also enhanced, as compared to the parent quaternary alloy [21]. 
Based on these studies, we are currently exploring the same strategy by using Mo addition into the initial $\mathrm{Ti}_{0.325} \mathrm{~V}_{0.275} \mathrm{Zr}_{0.125} \mathrm{Nb}_{0.275}$ alloy. The physicochemical and the hydrogen sorption properties of a new refractory HEA Ti $i_{0.30} \mathrm{~V}_{0.25} \mathrm{Zr}_{0.10} \mathrm{Nb}_{0.25} \mathrm{Mo}_{0.10}$ are reported here. Our aim is to highlight the effect of $10 \%$ addition of Mo on the structure, the microstructure, the chemical homogeneity and the hydrogen sorption performances of the parent composition. Large scale experiments at synchrotron (X-ray powder diffraction and total X-ray scattering for atomic pair distribution function analysis) and neutron sources (in situ neutron powder diffraction) have been employed to clarify the role of Mo and to compare to the analogous compositions previously reported [19-21].

\section{Materials and Methods}

The $\mathrm{Ti}_{0.30} \mathrm{~V}_{0.25} \mathrm{Zr}_{0.10} \mathrm{Nb}_{0.25} \mathrm{Mo}_{0.10}$ alloy was synthesized by high temperature arc melting under Ar atmosphere. The sample was turned and remelted 10 times to enhance the chemical homogeneity.

Structural characterizations were carried out by X-ray powder diffraction using both laboratory and synchrotron sources. The former investigation was carried out by the help of a D8 advance Bruker diffractometer ( $\mathrm{Cu} \mathrm{K} \alpha$ radiation, Bragg-Brentano geometry). Synchrotron X-ray powder diffraction (SR-XRD) was performed at the Cristal beamline in SOLEIL facility $(\lambda=0.7289 \AA)$. A capillary tube of $0.2 \mathrm{~mm}$ of diameter was filled with finely grounded hydride powder. The acquisition time was approximately $10 \mathrm{~min}$ for a scanning range from $1^{\circ}$ to $85^{\circ}(2 \theta)$. High-energy synchrotron XRD measurements were carried out ID15A beamline at ESRF, Grenoble (France) [22]. Incident flux was normalized using a diode placed in front of the sample. Diffraction patterns were collected in transmission geometry by using a Pilatus $3 \mathrm{X}$ CdTe $2 \mathrm{M}$ hybrid photon counting detector. A number of diffraction patterns were collected at slightly different detector positions for each sample, in order to minimize inhomogeneity effects and cover dead zones. The detector was offcentered with respect to the $99 \mathrm{keV}$ incident beam and positioned close to the sample to access $q$ values up to $\sim 30 \AA^{-1}$. The images were corrected for detector geometry, response, distortion, transparency and for the background contributions and X-ray polarization. Data were azimuthally integrated using a modified version [23] of the PyFAI library [24] to give one dimensional scattering patterns. The $G(r)$ were calculated from these patterns using routines from the Diffpy-CMI library [25] with local modifications for outlier rejection and treatment of background. The structural analysis was carried out using the PDFgui free software [26].

In situ and ex situ powder neutron diffraction $(\mathrm{nD})$ experiments on a deuterated sample were performed on the D1B beamline at the Institute Laue-Langevin $(\lambda=1.2858 \AA)$ with a scanning range from 1 to $128^{\circ}\left(2 \theta^{\circ}\right)$ DOI: 10.5291/ILL.DATA.CRG-2768. The ex situ measurements were performed using a vanadium container while the in situ measurements were performed on a silica tube containing the deuterated powder sample. The silica tube was connected to a secondary vacuum and the desorption step was carried out with a constant heating rate with $1{ }^{\circ} \mathrm{C} / \mathrm{min}$ while the evolved gas pressure was recorded by the help of a vacuum gauge.

For the sake of comparison, X-ray powder diffraction, total X-ray scattering at synchrotron and neutron powder diffraction experiments have been also recorded for the quaternary alloy $\mathrm{Ti}_{0.325} \mathrm{~V}_{0.275} \mathrm{Zr}_{0.125} \mathrm{Nb}_{0.275}$ under the same conditions.

The X-ray and neutron powder diffraction data were refined using the Rietveld method with Fullprof software [27]. The peak shape was described by Thompson-cox Hastings Pseudo Voigt function.

The microstructure of the alloy before and after cycling was analyzed by Scanning Electron Microscopy (SEM) acquiring back-scattered electron signal (BSE) using a Zeiss Merlin microscope. The chemical mapping of the sample was performed by energy dispersive X-ray spectroscopy (EDS). Prior to the microstructure measurement, the powder sample was embedded in a resin and coated with $1.9 \mathrm{~nm}$ of Pd. 
Hydrogen sorption properties were determined by measuring the Pressure-Composition Isotherms (PCI) at several temperatures, the kinetics of absorption at room temperature and the desorption profile by thermal desorption spectroscopy (TDS).

The PCI curves were recorded using a homemade volumetric device thermostated at $25{ }^{\circ} \mathrm{C}$. The sample was loaded in a stainless-steel container and activated by a heat treatment at $350{ }^{\circ} \mathrm{C}$ under dynamic vacuum for $3 \mathrm{~h}$. For the calculation of the hydrogen uptake, the real equation of state for hydrogen was acquired from the program GASPAK V3.32 (Cryodata. Inc., USA). Sequential absorption/desorption cycling measurements were performed using the same volumetric device. The absorption was performed at $50 \mathrm{bar} \mathrm{H}_{2}$ pressure at $25^{\circ} \mathrm{C}$, while the desorption was carried out by heating at $450{ }^{\circ} \mathrm{C}$ under dynamic vacuum for $12 \mathrm{~h}$. The kinetic curves were recorded only during the absorption step.

Thermal desorption spectroscopy (TDS) was used to determine the hydrogen desorption properties. Prior to the measurement, the sample was loaded in a quartz tube and evacuated under secondary vacuum. During desorption with a temperature ramp of $5^{\circ} \mathrm{C} / \mathrm{min}$ up to $445^{\circ} \mathrm{C}$, a mass spectrometer was used to record the evolved gases partial pressures and to follow the $\mathrm{H}_{2}$ desorption profile [28].

\section{Results and Discussions}

The composition $\mathrm{Ti}_{0.30} \mathrm{~V}_{0.25} \mathrm{Zr}_{0.10} \mathrm{Nb}_{0.25} \mathrm{Mo}_{0.10}$ possesses the following empirical parameters: $\mathrm{VEC}=4.7$ and $\delta=5.17 \%$. The data for the calculation of $\delta$ were taken from the reference [29].

The XRD of the as-cast material and the related Rietveld analysis indicated that the alloy crystallizes in a simple $b c c$ type structure (space group $\operatorname{Im} \overline{3} m$ ) with the unit cell $a_{b c c}=3.240$ (3) $\AA$ (Figure 1). For comparison, the lattice parameter of the single phase $b c c$ quaternary alloy $\mathrm{Ti}_{0.325} \mathrm{~V}_{0.275} \mathrm{Zr}_{0.125} \mathrm{Nb}_{0.275}$ prepared by the same method is higher than the present quinary composition, $a_{b c c}=3.261$ (1) $\AA$ [18]. Thus, the addition of 10 at. \% Mo to $\mathrm{Ti}_{0.325} \mathrm{~V}_{0.275} \mathrm{Zr}_{0.125} \mathrm{Nb}_{0.275}$ reduces the $b c c$ lattice parameter. This can be explained by the smaller atomic radius of Mo as compared to the other elements, except for $\mathrm{V}: \mathrm{r}_{\mathrm{V}}=1.31 \AA<\mathrm{r}_{\mathrm{Mo}}=1.36 \AA<\mathrm{r}_{\mathrm{Nb}}=1.43 \AA<\mathrm{r}_{\mathrm{Ti}}=1.45 \AA<\mathrm{r}_{\mathrm{Zr}}=1.59 \AA$. The average of radius of the quaternary composition is $\bar{r}=1.445 \AA$ and decreases after the addition of 10 at. \% Mo to $\bar{r}=1.428 \AA$, in line with the observed lattice parameter reduction. Moreover, the $\delta$ parameter decreases from $6 \%$ to $5.17 \%$ upon addition of 10 at. $\%$ of Mo into the quaternary alloy $\mathrm{Ti}_{0.325} \mathrm{~V}_{0.275} \mathrm{Zr}_{0.125} \mathrm{Nb}_{0.275}$.

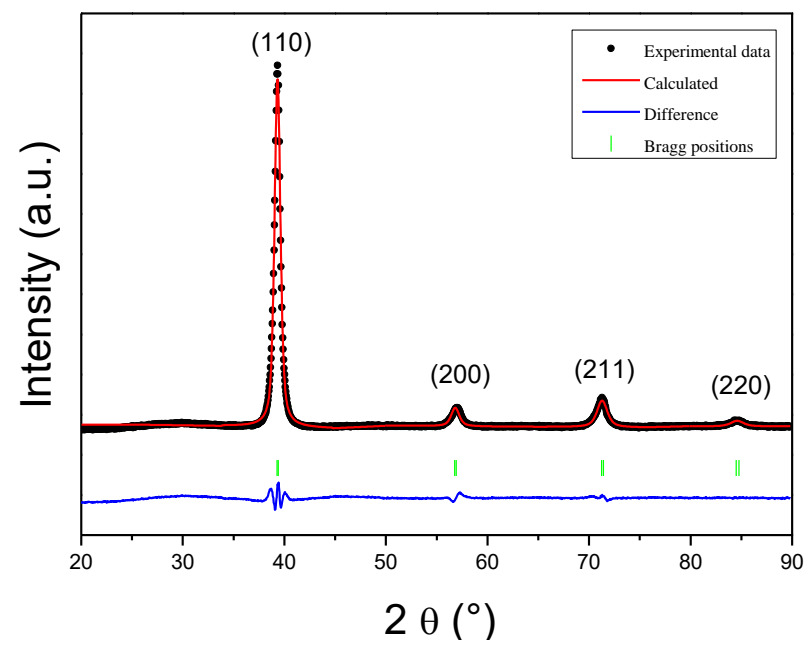

Figure 1. X-ray diffraction pattern $(\lambda=1.5406 \AA)$ with the corresponding Rietveld analysis of the as-cast $\mathrm{Ti}_{0.30} \mathrm{~V}_{0.25} \mathrm{Zr}_{0.10} \mathrm{Nb}_{0.25} \mathrm{Mo}_{0.10}$. This alloy is single-phased with a $b c c$ lattice. 
The chemical homogeneity of the as-cast alloy was investigated by SEM-EDS (Figure 2).

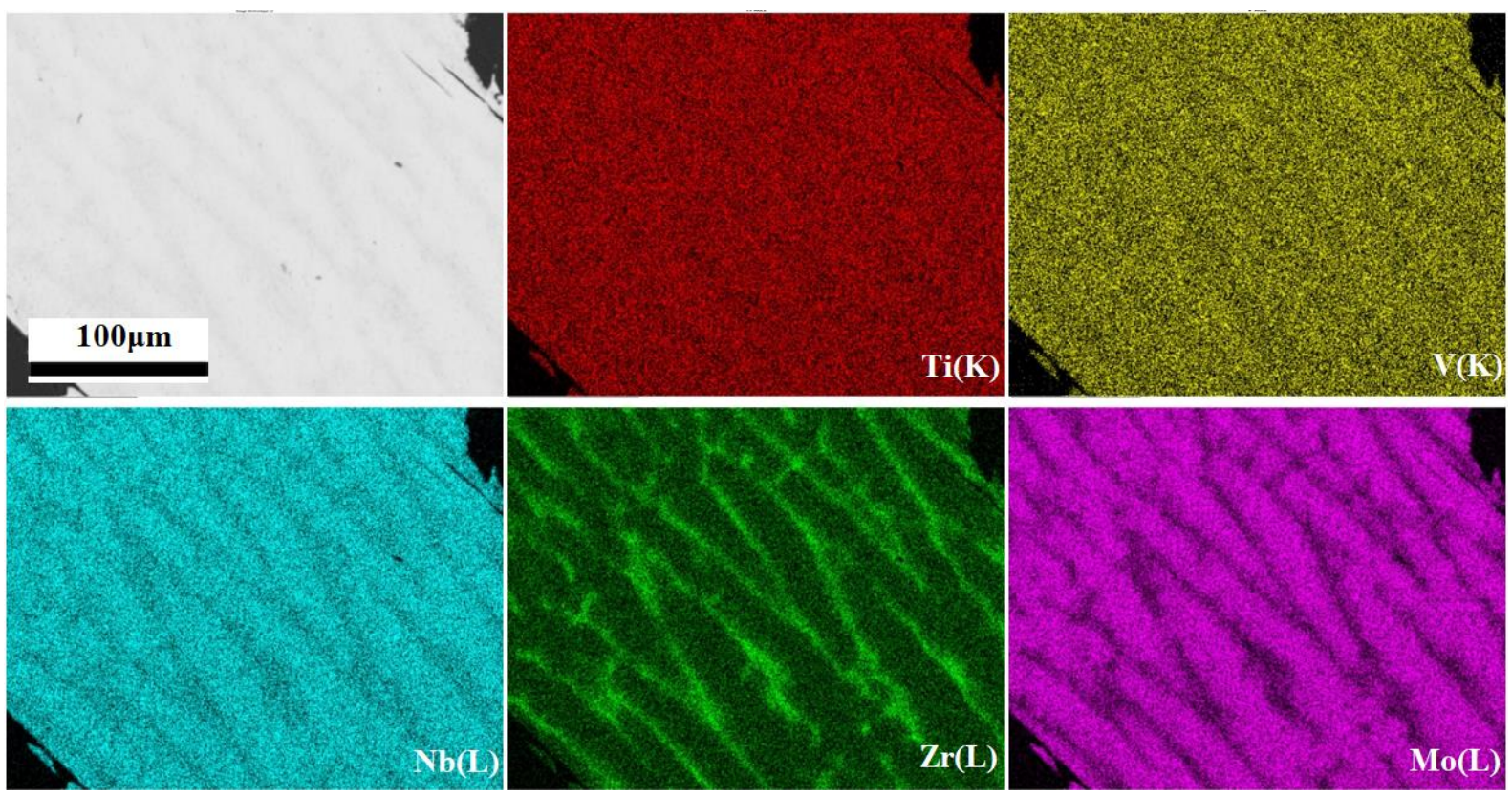

Figure 2. BSE image and EDS mapping analysis of the as-cast alloy $\mathrm{Ti}_{0.30} \mathrm{~V}_{0.25} \mathrm{Zr}_{0.10} \mathrm{Nb}_{0.25} \mathrm{Mo}_{0.10}$ alloy. The BSE image is in grey, and the five chemical elements are mapped as follows: $\mathrm{Ti}(\mathrm{K})$ —red, $\mathrm{V}(\mathrm{K})$ - yellow, $\mathrm{Nb}(\mathrm{L})$ —cyan, $\mathrm{Zr}(\mathrm{L})$ - green and Mo(L)-magenta.

The SEM-EDS analysis suggests a dendritic microstructure with small $\mathrm{Nb}$ and $\mathrm{Mo}$ enrichment, whereas the $\mathrm{Zr}$ concentration is slightly higher in the interdendritic regions (Table 1). The Ti and V are evenly distributed over both zones. Despite this dendritic microstructure occurring during the solidification of HEA, the overall composition is close to the nominal (Table 1).

Table 1. Chemical composition of the as-cast alloy in the overall, dendritic and interdendritic regions.

\begin{tabular}{cccccc}
\hline Region & $\begin{array}{c}\mathbf{T i} \\
\text { (at.\%) }\end{array}$ & $\begin{array}{c}\mathbf{V} \\
\text { (at.\%) }\end{array}$ & $\begin{array}{c}\mathbf{Z r} \\
\text { (at.\%) }\end{array}$ & $\begin{array}{c}\text { Nb } \\
\text { (at.\%) }\end{array}$ & $\begin{array}{c}\text { Mo } \\
\text { (at.\%) }\end{array}$ \\
\hline Dendritic & $28.2(0.5)$ & $22.9(0.2)$ & $6.2(0.4)$ & $29.8(0.7)$ & $12.9(0.4)$ \\
\hline Interdendritic & $30.4(0.4)$ & $25.5(0.7)$ & $23.6(1.7)$ & $15.9(2.4)$ & $4.9(1.2)$ \\
\hline Overall & $30.1(0.7)$ & $24.8(0.5)$ & $10.3(1.4)$ & $25.1(1.4)$ & $9.7(0.8)$ \\
\hline Nominal & 30 & 25 & 10 & 25 & 10 \\
\hline
\end{tabular}

Both XRD and SEM-EDS confirmed that the as-cast sample crystalizes in a single-phase $b c c$ lattice with an almost homogeneous chemical distribution.

The hydrogen sorption properties were studied using Sievert's method. The absorption PCI curves of the $\mathrm{Ti}_{0.30} \mathrm{~V}_{0.25} \mathrm{Zr}_{0.10} \mathrm{Nb}_{0.25} \mathrm{Mo}_{0.10}$ alloy were recorded at different temperatures (in the range $25^{\circ} \mathrm{C}$ to $300{ }^{\circ} \mathrm{C}$ ) to explore the effect of the temperature on the sorption properties (Figure 3).

All PCI curves show a single plateau at very low pressure, below the accuracy of the pressure transducer $\left(<10^{-2} \mathrm{bar}\right)$, irrespective of the temperature. No obvious signature of a two-step transition is noticed, as commonly encountered in the conventional bcc alloys, [30] or less often in some refractory HEAs [14]. The maximum hydrogen uptake at around 50 bar decreases with the increasing temperature from $2.0 \mathrm{H} / \mathrm{M}(2.8 \mathrm{wt} . \%)$ to around $1.0 \mathrm{H} / \mathrm{M}(1.4 \mathrm{wt} . \%)$ with increasing the temperature from $25^{\circ} \mathrm{C}$ to $300^{\circ} \mathrm{C}$. The absence of measurable plateau pressure with increasing the temperature hints to a very stable hydride 
phase, as also confirmed by our recent thermodynamic modelling for $b c c$ multicomponent alloys (see calculations details in Part SI-1) [31].

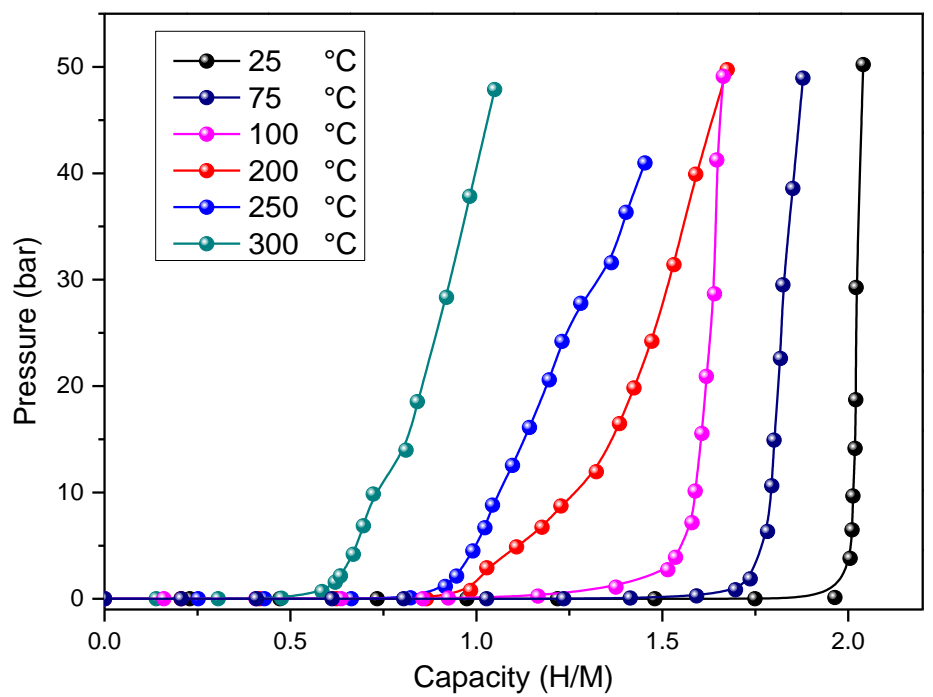

Figure 3. Pressure-Composition Isotherms at $25^{\circ} \mathrm{C}, 75^{\circ} \mathrm{C}, 100{ }^{\circ} \mathrm{C}, 200{ }^{\circ} \mathrm{C}, 250{ }^{\circ} \mathrm{C}$ and $300{ }^{\circ} \mathrm{C}$ of $\mathrm{Ti}_{0.30} \mathrm{~V}_{0.25} \mathrm{Zr}_{0.10} \mathrm{Nb}_{0.25} \mathrm{Mo}_{0.10}$.

The quaternary $\mathrm{Ti}_{0.325} \mathrm{~V}_{0.275} \mathrm{Zr}_{0.125} \mathrm{Nb}_{0.275}$ has a maximum hydrogen capacity of $1.75 \mathrm{H} / \mathrm{M}$ (2.47 wt.\%) [18] while the quinary composition $\mathrm{Ti}_{0.30} \mathrm{~V}_{0.25} \mathrm{Zr}_{0.10} \mathrm{Nb}_{0.25} \mathrm{Mo}_{0.10}$ reaches a maximum hydrogen absorption capacity of $2.0 \mathrm{H} / \mathrm{M}(2.8 \mathrm{wt} . \%)$. Therefore, the addition of $10 \%$ of Mo to the quaternary $\mathrm{Ti}_{0.325} \mathrm{~V}_{0.275} \mathrm{Zr}_{0.125} \mathrm{Nb}_{0.275}$ increases the maximum amount of the hydrogen uptake by $0.25 \mathrm{H} / \mathrm{M}$ reaching full capacity of the dihydride phase. Our previous studies on the effect of the addition of 10 at.\% of $\mathrm{Mg}$ [20], $\mathrm{Al}$ [19] and $\mathrm{Ta}$ [21] in the same quaternary alloy demonstrated that only Ta shows the same beneficial effect as Mo on the capacity, whereas $\mathrm{Mg}$ and $\mathrm{Al}$ additions decrease the maximum uptake from $1.75 \mathrm{H} / \mathrm{M}$ to $1.72 \mathrm{H} / \mathrm{M}$ and $1.6 \mathrm{H} / \mathrm{M}$ for $\mathrm{Mg}$ and $\mathrm{Al}$, respectively. A comparison with the values of maximum capacity, as expressed in wt.\%, from previous results is given in Table 2.

Table 2. Comparison of hydrogen storage properties of several refractory bcc HEAs.

\begin{tabular}{ccccc}
\hline Composition & Alloy & Hydride & $\begin{array}{c}\text { Capacity } \\
\text { (wt.\%) }\end{array}$ & Reference \\
\hline $\mathrm{Ti}_{0.30} \mathrm{~V}_{0.25} \mathrm{Zr}_{0.10} \mathrm{Nb}_{0.25} \mathrm{Mo}_{0.10}$ & $b c c$ & $f c c$ & 2.8 & present study \\
\hline $\mathrm{Ti}_{0.325} \mathrm{~V}_{0.275} \mathrm{Zr}_{0.125} \mathrm{Nb}_{0.275}$ & $b c c$ & $f c c$ & 2.47 & {$[18]$} \\
\hline $\mathrm{Ti}_{0.30} \mathrm{~V}_{0.25} \mathrm{Zr}_{0.10} \mathrm{Nb}_{0.25} \mathrm{Al}_{0.10}$ & $b c c$ & $b c t$ & 2.6 & {$[19]$} \\
\hline $\mathrm{Ti}_{0.30} \mathrm{~V}_{0.25} \mathrm{Zr}_{0.10} \mathrm{Nb}_{0.25} \mathrm{Mg}_{0.10}$ & $b c c$ & $f c c$ & 2.7 & {$[20]$} \\
\hline $\mathrm{Ti}_{0.30} \mathrm{~V}_{0.25} \mathrm{Zr}_{0.10} \mathrm{Nb}_{0.25} \mathrm{Ta}_{0.10}$ & $b c c$ & $f c c$ & 2.5 & {$[21]$} \\
\hline $\mathrm{TiVZrNbHf}$ & $b c c$ & $b c t$ & 2.7 & {$[9]$} \\
\hline $\mathrm{TiVNb}$ & $b c c$ & $f c c$ & 3 & {$[12]$} \\
\hline $\mathrm{TiVNbTa}$ & $b c c$ & $f c c$ & 2 & {$[12]$} \\
\hline $\mathrm{TiVNbCr}$ & $b c c$ & $f c c$ & 3.1 & {$[12]$} \\
\hline $\mathrm{TiZrNbHfTa}$ & $b c c$ & $f c c$ & 1.7 & {$[14]$} \\
\hline
\end{tabular}

In terms of gravimetric capacity, the studied quinary composition has a higher capacity of absorption than other $b c c$ alloys as $\mathrm{TiV}_{2}(2.6 \mathrm{wt} . \%)$ [32], classical intermetallics such as, $\mathrm{LaNi}_{5}$ (1.4 wt.\%) [32] or other HEAs like TiVNbTa (2 wt.\%) [12] and TiZrNbHfTa (1.7 wt.\%) [14].

The crystalline structure of the dihydride phase $\mathrm{Ti}_{0.30} \mathrm{~V}_{0.25} \mathrm{Zr}_{0.10} \mathrm{Nb}_{0.25} \mathrm{Mo}_{0.10} \mathrm{H}_{2}$ was studied by synchrotron X-ray powder diffraction (SR-XRD) (Figure 4a). The Rietveld 
analysis on SR-XRD patterns of the dihydride shows a single-phase hydride with a $f_{c c}$ structure $\left(\mathrm{CaF}_{2}\right.$-type with $\left.F m \overline{3} m\right)$ and lattice parameter $a_{f c c}=4.459$ (1) $\AA$ (Table 3). For complementary structural investigation of the hydride ex situ neutron powder diffraction was performed (Figure $4 \mathrm{~b}$ ). The deuterium was preferred to hydrogen in this experiment because of the high incoherent scattering of hydrogen atoms causing significant background. The $f c c$ lattice parameter by $\mathrm{nD}$ is $a_{f c c}=4.450$ (1) $\AA$ (Table 3), in good agreement with SR-XRD results. This technique of characterization enables us to locate the position of deuterium atoms inside the $f c c$ lattice of the deuteride. Using the Rietveld refinement, the deuterium atoms were located at the tetrahedral sites. This result is in agreement with previous studies on similar HEAs [10]. The SR-XRD and $\mathrm{nD}$ patterns together with the corresponding Rietveld refinements for $\mathrm{Ti}_{0.325} \mathrm{~V}_{0.275} \mathrm{Zr}_{0.125} \mathrm{Nb}_{0.275} \mathrm{H}_{1.7}$ are shown in Figures SI-2 and SI-3, while the obtained values for the $f c c$ lattice parameter are listed in Table 3.
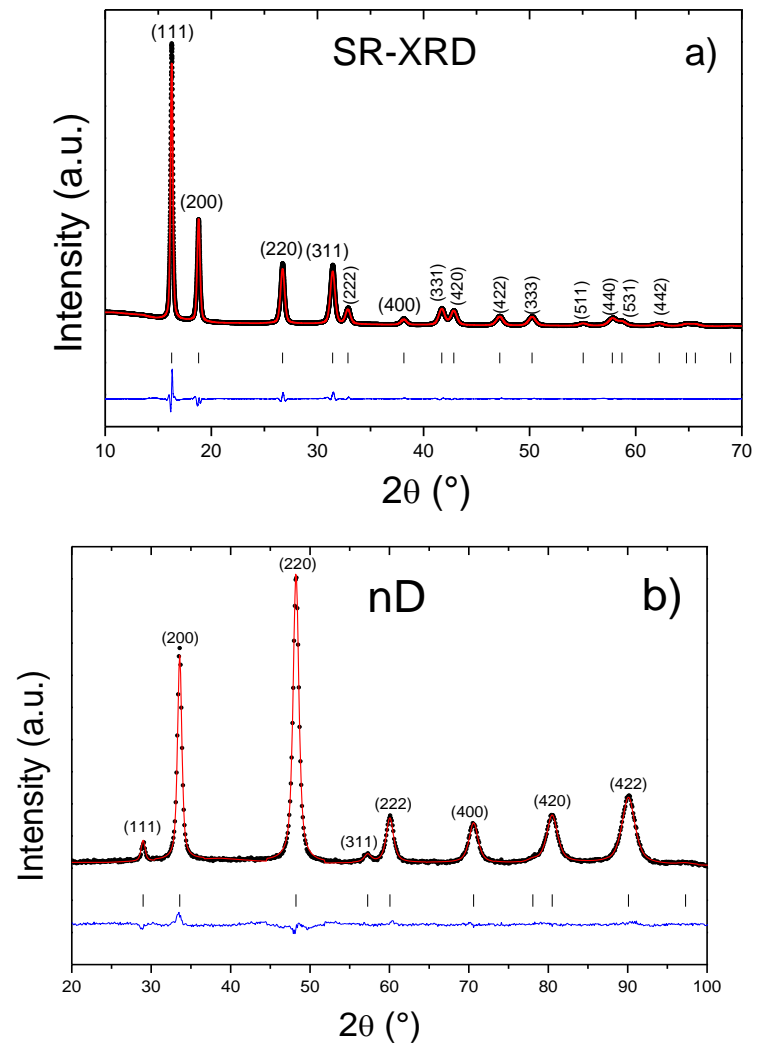

Figure 4. (a) SR-XRD pattern $(\lambda=0.7289 \AA)$ with the corresponding Rietveld analysis of the hydride $\mathrm{Ti}_{0.30} \mathrm{~V}_{0.25} \mathrm{Zr}_{0.10} \mathrm{Nb}_{0.25} \mathrm{Mo}_{0.10} \mathrm{H}_{2}$, (b) neutron powder diffraction data $(\lambda=1.2858 \AA$ ) with the corresponding Rietveld analysis of the deuteride $\mathrm{Ti}_{0.30} \mathrm{~V}_{0.25} \mathrm{Zr}_{0.10} \mathrm{Nb}_{0.25} \mathrm{Mo}_{0.10} \mathrm{D}_{2}$.

Table 3. The values of the $f c c$ lattice constant for the $\mathrm{Ti}_{0.325} \mathrm{~V}_{0.275} \mathrm{Zr}_{0.125} \mathrm{Nb}_{0.275} \mathrm{H}_{1.7}$ and $\mathrm{Ti}_{0.30} \mathrm{~V}_{0.25} \mathrm{Zr}_{0.10} \mathrm{Nb}_{0.25} \mathrm{Mo}_{0.10} \mathrm{H}_{2}$ hydrides from SR-XRD (CRISTAL at SOLEIL synchrotron), nD (D1B at ILL) and PDF analysis (ID15A at ESRF synchrotron). The mean squared displacement of elements, $U_{\text {iso }}$, is obtained from PDF modelling.

\begin{tabular}{ccccc}
\hline \multirow{2}{*}{ Sample } & \multicolumn{3}{c}{ FCC Lattice Parameter, $\boldsymbol{a}(\AA)$} & \multicolumn{2}{c}{$\boldsymbol{U}_{\text {iso }}\left(\AA^{2}\right)$} \\
\cline { 2 - 6 } & From SR-XRD & From nD & From PDF & From PDF \\
\hline $\mathrm{Ti}_{0.325} \mathrm{~V}_{0.275} \mathrm{Zr}_{0.125} \mathrm{Nb}_{0.275} \mathrm{H}_{1.7}$ & $4.478(1)$ & - & $4.482(2)$ & $0.009(1)$ \\
\hline $\mathrm{Ti}_{0.325} \mathrm{~V}_{0.275} \mathrm{Zr}_{0.125} \mathrm{Nb}_{0.275} \mathrm{D}_{1.7}$ & - & $4.475(1)$ & - & - \\
\hline $\mathrm{Ti}_{0.30} \mathrm{~V}_{0.25} \mathrm{Zr}_{0.10} \mathrm{Nb}_{0.25} \mathrm{Mo}_{0.10} \mathrm{H}_{2}$ & $4.459(1)$ & - & $4.466(2)$ & $0.014(5)$ \\
\hline $\mathrm{Ti}_{0.30} \mathrm{~V}_{0.25} \mathrm{Zr}_{0.10} \mathrm{Nb}_{0.25} \mathrm{Mo}_{0.10} \mathrm{D}_{2}$ & - & $4.450(1)$ & - & - \\
\hline
\end{tabular}


The short and medium-range orders of the full hydride phase were investigated by X-ray total scattering and related PDF analysis. PDF is described with the G(R) formalism, which indicates the probability of finding a pair of atoms separated by a distance $R$. The PDF obtained from Fourier transformation of the total scattering data shows the local structure of the hydride in terms of real-space distribution of interatomic distances. The modelling of the hydride phase was carried out using a $f_{c c}$ lattice with random distribution of all atoms on the crystallographic sites. For the sake of comparison, PDF data and related structural fit are compared to the quaternary hydride, see Figure 5.
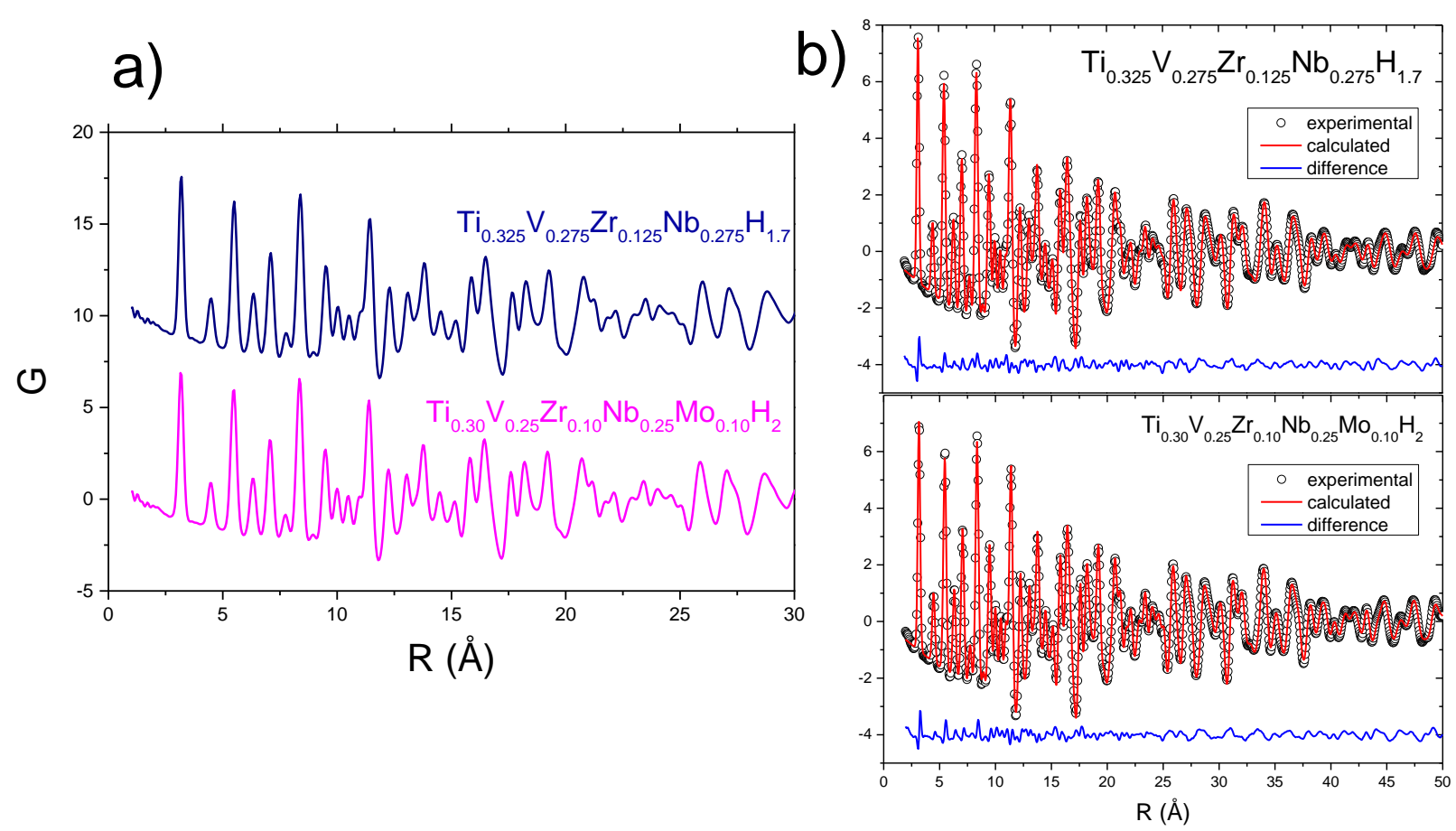

Figure 5. (a) PDF data of the $\mathrm{Ti}_{0.325} \mathrm{~V}_{0.275} \mathrm{Zr}_{0.125} \mathrm{Nb}_{0.275} \mathrm{H}_{1.7}$ and $\mathrm{Ti}_{0.30} \mathrm{~V}_{0.25} \mathrm{Zr}_{0.10} \mathrm{Nb}_{0.25} \mathrm{Mo}_{0.10} \mathrm{H}_{2}$ hydrides and (b) comparisons of the measured PDFs and their fits based on undistorted fcc random structure for both hydrides.

The PDF data of $\mathrm{Ti}_{0.325} \mathrm{~V}_{0.275} \mathrm{Zr}_{0.125} \mathrm{Nb}_{0.275} \mathrm{H}_{1.7}$ and $\mathrm{Ti}_{0.30} \mathrm{~V}_{0.25} \mathrm{Zr}_{0.10} \mathrm{Nb}_{0.25} \mathrm{Mo}_{0.10} \mathrm{H}_{2}$ hydrides have almost the same profile proving similar local order despite the addition of 10 at.\% of Mo into the initial quaternary alloy (Figure 5a). The difference curves between experimental and calculated PDF (Figure $5 b$ ) suggest that the undistorted random $f_{c c}$ model can well describe both the medium structure in the high- $R$ region and the local structure in the low- $R$ range, irrespective of the composition. Therefore, the average random $f_{c c}$ structure is able to explain all observed features in the PDF data without any evidence of local ordering or strong lattice distortion at short-range. Previous reports revealed that deviations from average structure are often considerable for $R<4 \AA$ especially, in the presence of large elements, such as $\mathrm{Zr}$ and $\mathrm{Hf}$ [33]. However, this is not the case presently, and we hypothesize that the small $\mathrm{Zr}$ content (12.5 at.\% and 10 at. $\%$ for the quaternary and quinary alloys, respectively) might be responsible for the formation of an average structure with random atoms distribution and small lattice distortion. Moreover, previous literature clearly demonstrated by combined X-ray and neutrons PDF analysis that the amount of lattice distortion is relieved when hydrides with $\mathrm{CaF}_{2}-$ type structures are formed from the $b c c$ refractory HEAs [34].

The refined $f_{c c}$ lattice parameters (a) from PDF modelling and the structural refinements of SR-XRD and $\mathrm{nD}$ data are listed in Table 3 together with the mean squared displacement of elements, $U_{\text {iso, }}$ as obtained from PDF analysis. The values of the $f c c$ lattice parameter from PDF are slightly larger than the ones from the diffraction assessments, irrespective of composition. Interestingly, $U_{\text {iso }}$ seems to increase by the addition of a fifth element, as expected, although this is within the error bar. 
Further investigations were made to study the hydrogen desorption properties from the $\mathrm{Ti}_{0.30} \mathrm{~V}_{0.25} \mathrm{Zr}_{0.10} \mathrm{Nb}_{0.25} \mathrm{Mo}_{0.10} \mathrm{H}_{2}$.

The thermo-desorption spectroscopy was performed on the deuteride $\mathrm{Ti}_{0.30} \mathrm{~V}_{0.25} \mathrm{Zr}_{0.10^{-}}$ $\mathrm{Nb}_{0.25} \mathrm{Mo}_{0.10} \mathrm{D}_{2}$ (Figure 6a). The onset temperature is around $150{ }^{\circ} \mathrm{C}$ marking the beginning of a plateau-like desorption followed by a main peak at $256^{\circ} \mathrm{C}$ indicating the maximum desorption rate and finally a second plateau-like desorption up to $400{ }^{\circ} \mathrm{C}$. The TDS profile of $\mathrm{Ti}_{0.325} \mathrm{~V}_{0.275} \mathrm{Zr}_{0.125} \mathrm{Nb}_{0.275}$ is relatively different from the quaternary alloy which is composed of one main peak with an onset temperature at $250^{\circ} \mathrm{C}$ and a maximum desorption rate at $287^{\circ} \mathrm{C}[18,21]$.
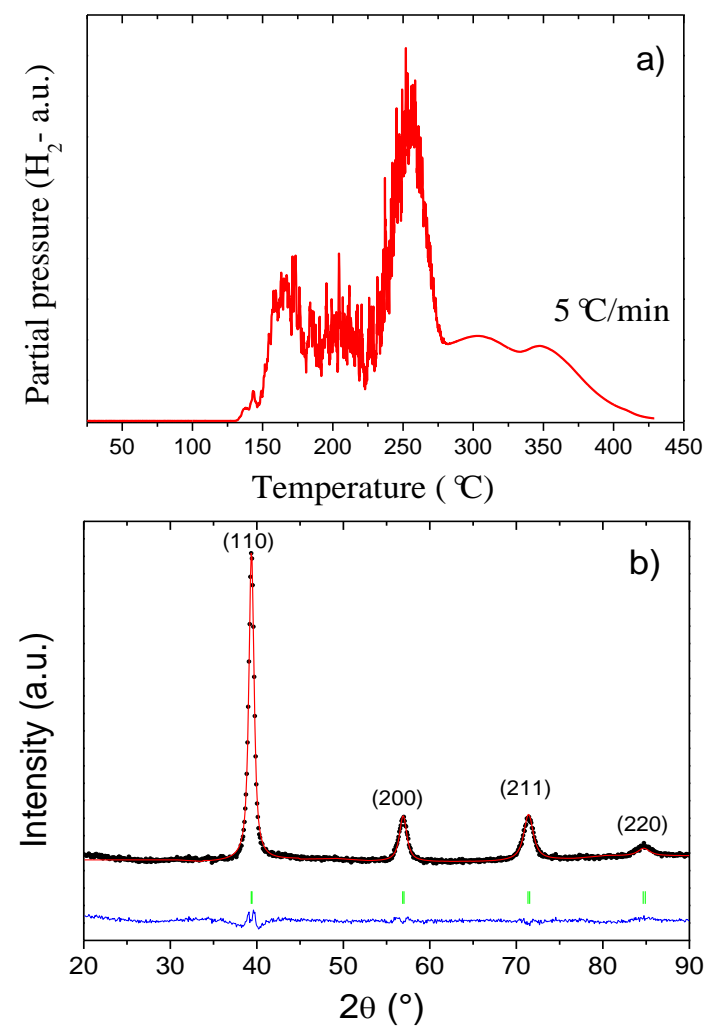

Figure 6. (a) TDS profile for the hydrogen desorption from $\mathrm{Ti}_{0.30} \mathrm{~V}_{0.25} \mathrm{Zr}_{0.10} \mathrm{Nb}_{0.25} \mathrm{Mo}_{0.10} \mathrm{D}_{2}$. (b) XRD $(\lambda=1.5406 \AA)$ of the $\mathrm{Ti}_{0.30} \mathrm{~V}_{0.25} \mathrm{Zr}_{0.10} \mathrm{Nb}_{0.25} \mathrm{Mo}_{0.10} \mathrm{D}_{2}$ after desorption with the corresponding Rietveld analysis.

The addition of 10 at.\% Mo to the quaternary composition decreases the temperature of the maximum desorption rate from $287^{\circ} \mathrm{C}$ to $256^{\circ} \mathrm{C}$ and the onset temperature from $250{ }^{\circ} \mathrm{C}$ to $150{ }^{\circ} \mathrm{C}$. Our previous studies proved that the addition of 10 at. $\%$ of other elements to the quaternary $\mathrm{Ti}_{0.325} \mathrm{~V}_{0.275} \mathrm{Zr}_{0.125} \mathrm{Nb}_{0.275}$ results in a modification of TDS profile. For example, the desorption profile of $\mathrm{Mg}_{0.10} \mathrm{Ti}_{0.30} \mathrm{~V}_{0.25} \mathrm{Zr}_{0.10} \mathrm{Nb}_{0.25}$ is similar to the quaternary alloy with one main desorption peak at relatively high temperature [20], whereas for $\mathrm{Al}_{0.10} \mathrm{Ti}_{0.30} \mathrm{~V}_{0.25} \mathrm{Zr}_{0.10} \mathrm{Nb}_{0.25}$ the TDS profile drastically changes with a main desorption peak at low temperature $\left(\sim 130^{\circ} \mathrm{C}\right)$ followed by a small and broad peak at high temperature [19]. The desorption profile is also modified for $\mathrm{Ta}_{0.10} \mathrm{Ti}_{0.30} \mathrm{~V}_{0.25} \mathrm{Zr}_{0.10} \mathrm{Nb}_{0.25}$ with two main desorption events at low and high temperatures $\left(\sim 160{ }^{\circ} \mathrm{C}\right.$ and $260{ }^{\circ} \mathrm{C}$, respectively) [21]. Thus, the desorption properties change drastically depending on the nature of the fifth element into the initial quaternary composition.

To better understand the reversibility hydrogen absorption and desorption for this composition, we investigated the crystalline structure of the desorbed sample after the TDS measurement. The XRD pattern and the corresponding Rietveld refinement of the desorbed sample (Figure $6 \mathrm{~b}$ ) shows a full recovery of the initial $b c c$ structure with a lattice parameter 
$a_{b c c}=3.235(2) \AA$ A close to the initial value. No phase segregation nor decomposition could be noticed by desorption proving complete reversibility under these conditions.

To further investigate the structural phase transition accompanying the hydrogen desorption, we carried out in situ neutron diffraction (Figure 7).

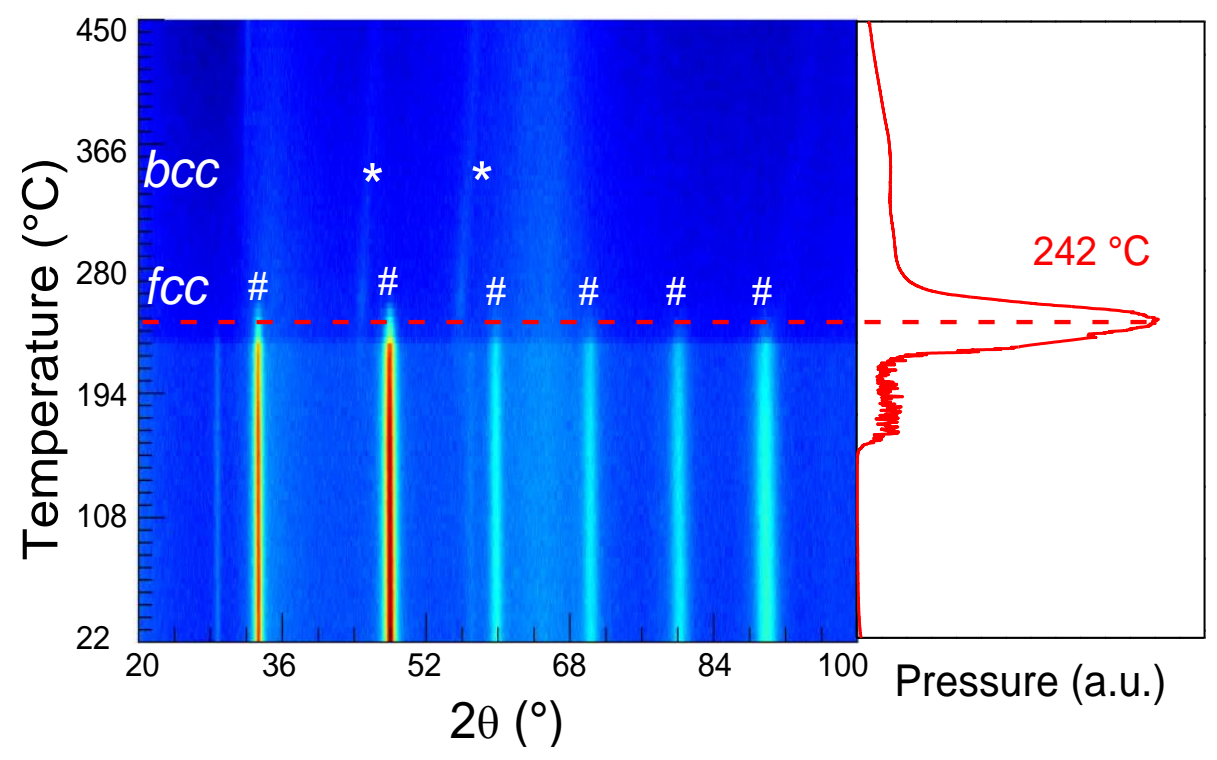

Figure 7. In situ neutron diffraction $(\lambda=1.2858 \AA)$ of $\mathrm{Ti}_{0.30} \mathrm{~V}_{0.25} \mathrm{Zr}_{0.10} \mathrm{Nb}_{0.25} \mathrm{Mo}_{0.10} \mathrm{D}_{2}$ with a heating rate of $1{ }^{\circ} \mathrm{C} / \mathrm{min}$ under dynamic vacuum (left). The desorption profile during neutron diffraction (right). The initial $f_{c c}$ deuteride and the final $b c c$ desorbed phases are marked with \# and ${ }^{*}$, respectively.

The deuterium desorption from the $\mathrm{Ti}_{0.30} \mathrm{~V}_{0.25} \mathrm{Zr}_{0.10} \mathrm{Nb}_{0.25} \mathrm{Mo}_{0.10} \mathrm{D}_{2}$ occurs within three steps, as shown from the vacuum pressure reading during in situ neutron diffraction (Figure 7 right), in agreement with the TDS profile. First event is a plateau-like desorption followed by a major peak at $242{ }^{\circ} \mathrm{C}$ and finally a broad desorption is noticed at high temperature.

The initial phase corresponding to the $f c c$ deuteride (marked with \#) is stable with rising the temperature up to around $200{ }^{\circ} \mathrm{C}$ where the peaks intensity decreases. Surprisingly, the first desorption event starting at around $150{ }^{\circ} \mathrm{C}$ is not accompanied by any noticeable phase transition or, at least, loss in the peak's intensity. Further increase in temperature triggers a sharp phase transition at $242{ }^{\circ} \mathrm{C}$ (in agreement with the TDS experiment) from $f_{c c}$ deuteride to $b c c$ phase (marked with *). The diffraction signals of the desorbed $b c c$ phase are not intense due to the low thermal neutron cross section of the elements in the composition, in agreement with our previous studies [19-21]. Furthermore, this composition might be a good candidate for an in-core, light water reactor environment [35].

These experiments confirmed that the hydrogen absorption and desorption reactions are fully reversible in $\mathrm{Ti}_{0.30} \mathrm{~V}_{0.25} \mathrm{Zr}_{0.10} \mathrm{Nb}_{0.25} \mathrm{Mo}_{0.10}$ and occur within a single-step transformation from $b c c \leftrightarrow f c c$, as also proposed for the quaternary alloy [21]. Therefore, it will be interesting to study the hydrogen absorption/desorption stability properties for 20 cycles (Figure 8a). For each absorption step at room temperature the kinetics curves were measured (Figure $8 b$ ). The desorption was realized by heating at high temperature under dynamic vacuum. 

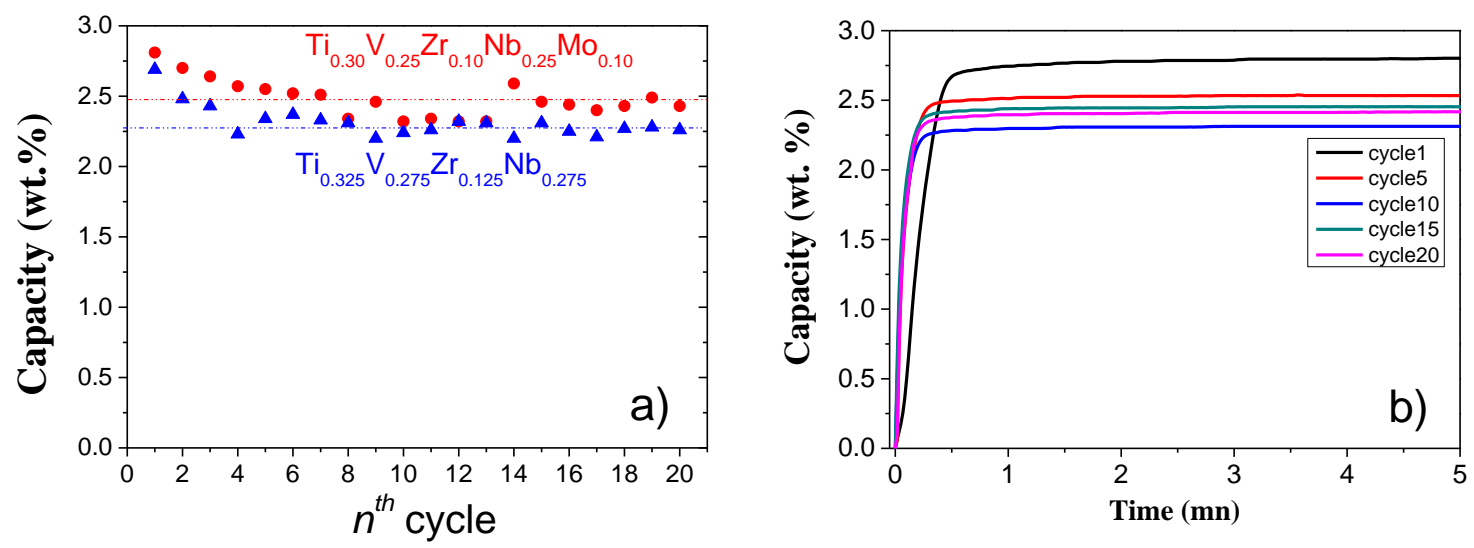

Figure 8. (a) Hydrogen absorption capacity during 20 cycles for $\mathrm{Ti}_{0.30} \mathrm{~V}_{0.25} \mathrm{Zr}_{0.10} \mathrm{Nb}_{0.25} \mathrm{Mo}_{0.10}$ and $\mathrm{Ti}_{0.325} \mathrm{~V}_{0.275} \mathrm{Zr}_{0.125} \mathrm{Nb}_{0.275}$ alloys. (b) Hydrogen absorption kinetic curves at room temperature for $\mathrm{Ti}_{0.30} \mathrm{~V}_{0.25} \mathrm{Zr}_{0.10} \mathrm{Nb}_{0.25} \mathrm{Mo}_{0.10}$ during 20 cycles.

The quaternary alloy synthesized by arc melting loses capacity from $1.8 \mathrm{H} / \mathrm{M}(2.7 \mathrm{wt} . \%)$ to $1.5 \mathrm{H} / \mathrm{M}(2.3 \mathrm{wt} . \%)$ after the first four cycles followed by stabilization [18]. A similar drop of the capacity is also observed for the quinary alloy from $2.0 \mathrm{H} / \mathrm{M}(2.8 \mathrm{wt} . \%)$ to $1.7 \mathrm{H} / \mathrm{M}$ (2.47 wt.\%) followed by stabilization (Figure 8a). Fading of the capacity during cycling is currently observed in many HEAs, although this issue is still not clearly understood [36,37]. Compositions with the refractory elements were also studied previously for their cycling properties, for example, Nygård et al. stated that TiVNbTa alloy has a capacity of $0.85 \mathrm{H} / \mathrm{M}$ after the first cycle but the reversible capacity is reduced to zero after only 5 cycles [12] Montero et.al. studied the cycling properties of $\mathrm{Al}_{0.10} \mathrm{Ti}_{0.30} \mathrm{~V}_{0.25} \mathrm{Zr}_{0.10} \mathrm{Nb}_{0.25}$ alloy which proves an increased reversible gravimetric capacity as compared to the quaternary alloy from $2.25 \mathrm{wt}$. $\%$ to $2.45 \mathrm{wt} . \%$, respectively, i.e., cycling stability boosts from $85 \%$ to $94 \%$ by adding $\mathrm{Al}[19]$.

In conclusion, the effect of $10 \%$ addition of Mo into the quaternary alloy increases the capacity of the first cycle and the reversible uptake relative to the initial composition.

The capacity loss could be explained by both extrinsic and intrinsic factors. The former ones include vacuum or gas contaminants that can affect the surface of the sample either by oxidation or adsorption of hydrocarbons on the surface thus reducing the volume of the alloy able to react with hydrogen. The intrinsic factors comprise the phenomenon of phase disproportionation accompanied by the formation of stable monohydride phases such as $\mathrm{TiH}_{2}, \mathrm{VH}_{2}$, the inhomogeneities in the chemical composition, the kinetic issues that may lead to incomplete absorption or desorption and the decrease in the degree of crystallinity.

The absorption kinetics (Figure $8 \mathrm{~b}$ ) indicate that around $90 \%$ of the full capacity is reached within $30 \mathrm{~s}$ on the first cycle and $20 \mathrm{~s}$ for further cycling. This behavior can be explained by decrepitation of the material during cycling: large and clean surfaces are created to react and dissociate hydrogen molecules together with faster hydrogen atoms diffusion into smaller grains of the alloy.

To further investigate the effect of cycling on the microstructure and the chemical homogeneity we have performed SEM-EDS after cycling (Figure 9).

The BSE image shows the effect of hydrogen embrittlement on the material with the formation of numerous cracks. The EDS chemical mapping shows the same homogenous distribution of the elements as the initial sample. The same microstructure as the as-cast material is observed despite cycling: $\mathrm{Nb}$ - and Mo-rich dendritic zones coexist with $\mathrm{Zr}$-rich interdendritic regions.

The hydrogen cycling might affect the crystalline structure of the alloy. To assess this effect XRD and Rietveld analysis have been carried out for the cycled sample (Figure 10). 


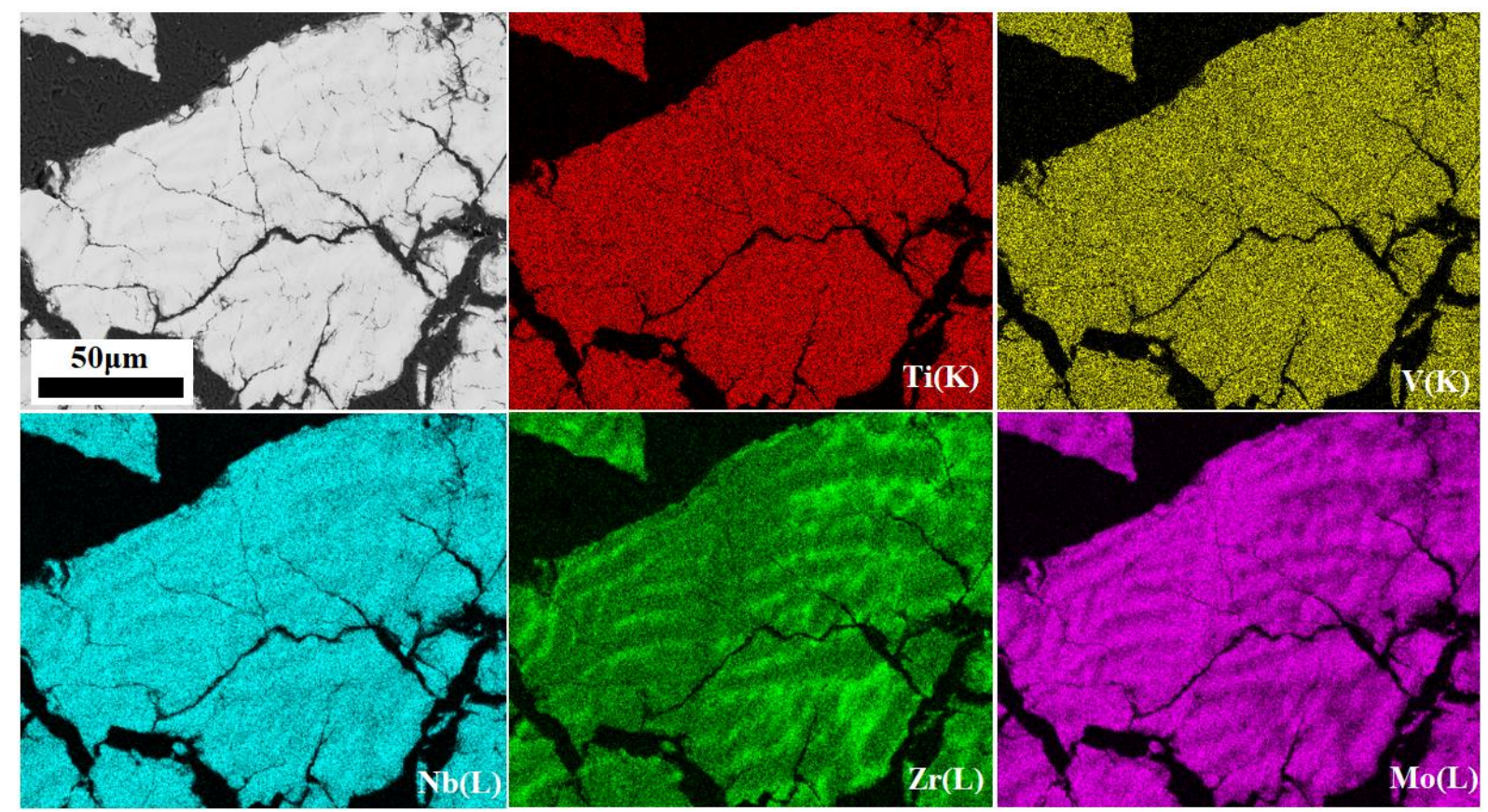

Figure 9. BSE image and EDS mapping analysis of $\mathrm{Ti}_{0.30} \mathrm{~V}_{0.25} \mathrm{Zr}_{0.10} \mathrm{Nb}_{0.25} \mathrm{Mo}_{0.10}$ alloy after 20 hydrogen absorption/desorption cycles.

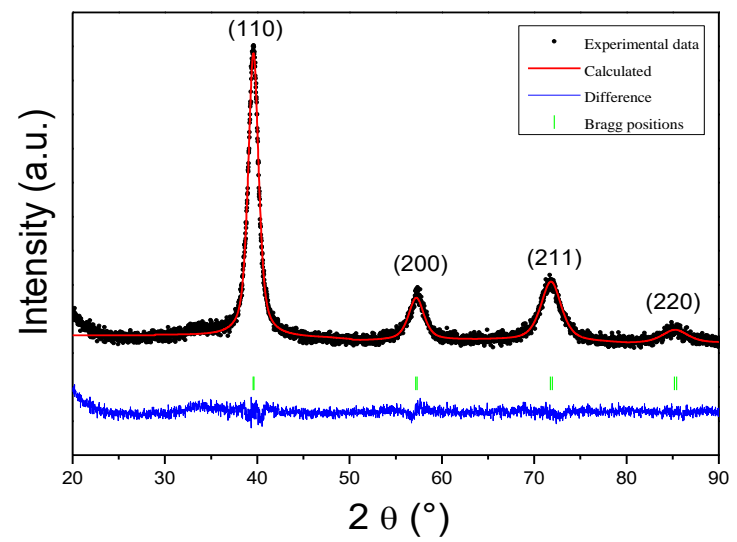

Figure 10. $\mathrm{XRD}\left(\lambda=1.5406 \AA\right.$ ) of the $\mathrm{Ti}_{0.30} \mathrm{~V}_{0.25} \mathrm{Zr}_{0.10} \mathrm{Nb}_{0.25} \mathrm{Mo}_{0.10}$ after 20 cycles (desorbed state) with the corresponding Rietveld analysis.

These results show that the cycled sample is single phased with a $b c c$ lattice, the same as the initial material. Consequently, no phase segregation is noticed after cycling that might explain the initial fading of the capacity during cycling. The lattice parameter of the cycled alloy is $a_{b c c}=3.219$ (4) $\AA$, which is slightly smaller than the as-cast sample $\left(a_{b c c}=3.240\right.$ (3) $\AA$ ). However, after 20 cycles, a peak broadening occurs as also demonstrated by the increase of the full width at half maximum (FWHM) listed in Table 4 for the three main diffraction peaks. This peak broadening might be responsible for the discrepancy in the lattice parameter via enhanced uncertainties in the lattice determination. Moreover, peak broadening might suggest a slight loss of the degree of crystallinity that may account for the initial loss of capacity during cycling, although this latter issue is still under debate. 
Table 4. Lattice parameter, FWHM of (110), (200) and (211) diffraction peaks for the as-cast sample and the desorbed sample after 20 cycles.

\begin{tabular}{ccccc}
\hline & \multicolumn{2}{c}{ As-Cast } & \multicolumn{2}{c}{ After 20-Cycles } \\
\hline $\mathbf{a}(\AA)$ & $\mathbf{3 . 2 4 0}(\mathbf{3})$ & \multicolumn{2}{c}{$\mathbf{3 . 2 1 9}(\mathbf{4})$} \\
\hline Miller Indices & $\mathbf{2 \theta}\left(^{\circ}\right)$ & FWHM $\left(^{\circ}\right)$ & $\mathbf{2 \theta}\left(^{\circ}\right)$ & FWHM $\left(^{\circ}\right)$ \\
\hline$(110)$ & 39.54 & 0.642 & 39.57 & 1.286 \\
\hline$(200)$ & 57.21 & 1.017 & 57.39 & 1.620 \\
\hline$(211)$ & 71.49 & 0.993 & 71.65 & 2.314 \\
\hline
\end{tabular}

\section{Conclusions}

A single-phased $b c c$ alloy with composition $\mathrm{Ti}_{0.30} \mathrm{~V}_{0.25} \mathrm{Zr}_{0.10} \mathrm{Nb}_{0.25} \mathrm{Mo}_{0.10}$ was prepared by arc melting with excellent chemical homogeneity, as confirmed by XRD and SEM-EDS. This alloy rapidly absorbs hydrogen at room temperature forming a hydride phase with maximum $2.0 \mathrm{H} / \mathrm{M}$ capacity. The phase transition from metal to hydride seems to occur within a single step, irrespective of the temperature. The hydride phase was thoroughly characterized by synchrotron X-ray scattering complemented by neutron diffraction. Synchrotron X-ray and neutron diffraction reveal the formation of a single-phased $f c c$ hydride whereas, at more local level, PDF analysis points out that the hydride phase possesses an average $f c c$ structure with random atoms distribution and small lattice distortion. Hydrogen atoms occupy the tetrahedral interstitial sites of the $f c c$ hydride phase. The desorption reaction takes place at high temperature. The reaction with hydrogen is fully reversible since the initial $b c c$ phase is recovered after absorption/desorption cycling. The in situ neutron diffraction experiment during deuterium desorption seems to indicate a single step phase transition from $f_{c c}$ hydride to initial $b c c$ lattice. Despite an initial fading in the first cycles, the absorption capacity stabilizes to around $1.7 \mathrm{H} / \mathrm{M}(2.47 \mathrm{wt} . \%)$ for further cycling. Cycling is accompanied by a small loss of crystallinity that might explain the initial capacity decrease. Moreover, the cycling preserves the alloy and hydride structures without introducing phase segregation or chemical inhomogeneities and increases the absorption reaction kinetics at room temperature. The findings here demonstrate that the addition of 10 at.\% of Mo into the quaternary $\mathrm{Ti}_{0.325} \mathrm{~V}_{0.275} \mathrm{Zr}_{0.125} \mathrm{Nb}_{0.275}$ alloy improves the hydrogen storage performances. Owing to the vast possibilities of compositions these insights can help the progress of the research for the design of novel and performant HEAs as solid-state stores.

Supplementary Materials: The following are available online at https:/ /www.mdpi.com/article/ 10.3390/hydrogen2040022/s1, Part SI-1: Thermodynamic modelling of the Pressure-CompositionIsotherm for the $\mathrm{Ti}_{0.30} \mathrm{~V}_{0.25} \mathrm{Zr}_{0.10} \mathrm{Nb}_{0.25} \mathrm{Mo}_{0.10}$ composition at $25^{\circ} \mathrm{C}$. Figure SI-2: SR-XRD pattern together with the corresponding Rietveld refinement for $\mathrm{Ti}_{0.325} \mathrm{~V}_{0.275} \mathrm{Zr}_{0.125} \mathrm{Nb}_{0.275} \mathrm{H}_{1.7}$. Figure SI-3: $\mathrm{nD}$ pattern and related Rietveld refinement for $\mathrm{Ti}_{0.325} \mathrm{~V}_{0.275} \mathrm{Zr}_{0.125} \mathrm{Nb}_{0.275} \mathrm{D}_{1.7}$.

Author Contributions: Conceptualization, C.Z.; Methodology, C.Z., L.L., V.N., G.Z.; Formal Analysis, A.B., C.Z.; Investigation, A.B., L.L., G.V., V.N., C.Z.; Validation, C.Z., L.L., V.N., G.V., G.Z.; WritingOriginal Draft Preparation, A.B. and C.Z.; Writing-Review and Editing, A.B., L.L., G.Z., G.V., V.N., C.Z.; Funding Acquisition, C.Z. and L.L. All authors have read and agreed to the published version of the manuscript.

Funding: C.Z., A.B., L.L. and V.N. acknowledge the French National Research Agency (ANR) for the financial support for the MASSHY project (ANR-19- CE05-0029-01).

Acknowledgments: We acknowledge 2FDN for beamtime allocation on the CRG-D1B beamline. Sofien Djellit from ILL and Fabrice Couturas from ICMPE are acknowledged for help with neutron diffraction at ILL. In the framework of the CNRS ЯÉCIPROCS network, this work has been accepted for synchrotron beamtime by the Soleil scientific proposal committee (BAG proposal 20191509). CZ would like to thank Erik Elkaim and Benoit Baptiste for their help and organization of BAG beamtime on CRISTAL beamline at SOLEIL. 
Conflicts of Interest: The authors declare no conflict of interest.

\section{References}

1. Bellosta von Colbe, J.; Ares, J.-R.; Barale, J.; Baricco, M.; Buckley, C.; Capurso, G.; Gallandat, N.; Grant, D.M.; Guzik, M.N.; Jacob, I.; et al. Application of Hydrides in Hydrogen Storage and Compression: Achievements, Outlook and Perspectives. Int. J. Hydrogen Energy 2019, 44, 7780-7808. [CrossRef]

2. Yeh, J.; Chen, S.; Lin, S.; Gan, J.; Chin, T.; Shun, T.; Tsau, C.; Chang, S. Nanostructured High-Entropy Alloys with Multiple Principal Elements: Novel Alloy Design Concepts and Outcomes. Adv. Eng. Mater. 2004, 6, 299-303. [CrossRef]

3. Cantor, B.; Chang, I.T.H.; Knight, P.; Vincent, A.J.B. Microstructural Development in Equiatomic Multicomponent Alloys. Mater. Sci. Eng. A 2004, 375-377, 213-218. [CrossRef]

4. Gao, M.C.; Yeh, J.-W.; Liaw, P.K.; Zhang, Y. High-Entropy Alloys Fundamentals and Applications; Springer International Publishing: Cham, Switzerland, 2016; Chapter 10; ISBN 978-3-319-27011-1.

5. Couzinié, J.-P.; Dirras, G. Body-Centered Cubic High-Entropy Alloys: From Processing to Underlying Deformation Mechanisms. Mater. Charact. 2019, 147, 533-544. [CrossRef]

6. Miracle, D.B.; Senkov, O.N. A Critical Review of High Entropy Alloys and Related Concepts. Acta Mater. 2017, 122, 448-511. [CrossRef]

7. King, D.J.M.; Middleburgh, S.C.; McGregor, A.G.; Cortie, M.B. Predicting the Formation and Stability of Single Phase HighEntropy Alloys. Acta Mater. 2016, 104, 172-179. [CrossRef]

8. Fukai, Y. The Metal-Hydrogen System; Springer: Berlin/Heidelberg, Germany, 2005.

9. Sahlberg, M.; Karlsson, D.; Zlotea, C.; Jansson, U. Superior Hydrogen Storage in High Entropy Alloys. Sci. Rep. 2016, 6, 36770. [CrossRef] [PubMed]

10. Karlsson, D.; Ek, G.; Cedervall, J.; Zlotea, C.; Møller, K.T.; Hansen, T.C.; Bednarčík, J.; Paskevicius, M.; Sørby, M.H.; Jensen, T.R.; et al. Structure and Hydrogenation Properties of a HfNbTiVZr High-Entropy Alloy. Inorg. Chem. 2018, 57, 2103-2110. [CrossRef]

11. Zepon, G.; Leiva, D.R.; Strozi, R.B.; Bedoch, A.; Figueroa, S.J.A.; Ishikawa, T.T.; Botta, W.J. Hydrogen-Induced Phase Transition of MgZrTiFe0.5Co0.5Ni0.5 High Entropy Alloy. Int. J. Hydrogen Energy 2018, 43, 1702-1708. [CrossRef]

12. Nygård, M.M.; Ek, G.; Karlsson, D.; Sørby, M.H.; Sahlberg, M.; Hauback, B.C. Counting Electrons-A New Approach to Tailor the Hydrogen Sorption Properties of High-Entropy Alloys. Acta Mater. 2019, 175, 121-129. [CrossRef]

13. Shen, H.; Zhang, J.; Hu, J.; Zhang, J.; Mao, Y.; Xiao, H.; Zhou, X.; Zu, X. A Novel TiZrHfMoNb High-Entropy Alloy for Solar Thermal Energy Storage. Nanomaterials 2019, 9, 248. [CrossRef]

14. Zlotea, C.; Sow, M.A.; Ek, G.; Couzinié, J.-P.; Perrière, L.; Guillot, I.; Bourgon, J.; Møller, K.T.; Jensen, T.R.; Akiba, E.; et al. Hydrogen Sorption in TiZrNbHfTa High Entropy Alloy. J. Alloys Compd. 2019, 775, 667-674. [CrossRef]

15. Strozi, R.B.; Leiva, D.R.; Huot, J.; Botta, W.J.; Zepon, G. Synthesis and Hydrogen Storage Behavior of Mg-V-Al-Cr-Ni High Entropy Alloys. Int. J. Hydrogen Energy 2021, 46, 2351-2361. [CrossRef]

16. Ek, G.; Nygård, M.M.; Pavan, A.F.; Montero, J.; Henry, P.F.; Sørby, M.H.; Witman, M.; Stavila, V.; Zlotea, C.; Hauback, B.C.; et al. Elucidating the Effects of the Composition on Hydrogen Sorption in TiVZrNbHf-Based High-Entropy Alloys. Inorg. Chem. 2021, 60, 1124-1132. [CrossRef] [PubMed]

17. Kunce, I.; Polanski, M.; Bystrzycki, J. Microstructure and Hydrogen Storage Properties of a TiZrNbMoV High Entropy Alloy Synthesized Using Laser Engineered Net Shaping (LENS). Int. J. Hydrogen Energy 2014, 39, 9904-9910. [CrossRef]

18. Montero, J.; Zlotea, C.; Ek, G.; Crivello, J.-C.; Laversenne, L.; Sahlberg, M. TiVZrNb Multi-Principal-Element Alloy: Synthesis Optimization, Structural, and Hydrogen Sorption Properties. Molecules 2019, 24, 2799. [CrossRef] [PubMed]

19. Montero, J.; Ek, G.; Laversenne, L.; Nassif, V.; Sahlberg, M.; Zlotea, C. How 10 At.\% Al Addition in the Ti-V-Zr-Nb High-Entropy Alloy Changes Hydrogen Sorption Properties. Molecules 2021, 26, 2470. [CrossRef]

20. Montero, J.; Ek, G.; Sahlberg, M.; Zlotea, C. Improving the Hydrogen Cycling Properties by Mg Addition in Ti-V-Zr-Nb Refractory High Entropy Alloy. Scr. Mater. 2021, 194, 113699. [CrossRef]

21. Montero, J.; Ek, G.; Laversenne, L.; Nassif, V.; Zepon, G.; Sahlberg, M.; Zlotea, C. Hydrogen Storage Properties of the Refractory Ti-V-Zr-Nb-Ta Multi-Principal Element Alloy. J. Alloys Compd. 2020, 835, 155376. [CrossRef]

22. Vaughan, G.B.M.; Baker, R.; Barret, R.; Bonnefoy, J.; Buslaps, T.; Checchia, S.; Duran, D.; Fihman, F.; Got, P.; Kieffer, J. ID15A at the ESRF a beamline for high speed operando X-ray diffraction, diffraction tomography and total scattering. J. Synchrotron Radiat. 2020, 27, 515-528. [CrossRef] [PubMed]

23. Kieffer, J.; Petitdemange, S.; Vincent, T. Real-Time Diffraction Computed Tomography Data Reduction. J. Synchrotron Radiat. 2018, 25, 612-617. [CrossRef]

24. Ashiotis, G.; Deschildre, A.; Nawaz, Z.; Wright, J.P.; Karkoulis, D.; Picca, F.E.; Kieffer, J. The Fast Azimuthal Integration Python Library: PyFAI. J. Appl. Crystallogr. 2015, 48, 510-519. [CrossRef]

25. Juhás, P.; Farrow, C.L.; Yang, X.; Knox, K.R.; Billinge, S.J.L. Complex Modeling: A Strategy and Software Program for Combining Multiple Information Sources to Solve Ill Posed Structure and Nanostructure Inverse Problems. Acta Crystallogr. Sect. Found. Adv. 2015, 71, 562-568. [CrossRef]

26. Farrow, C.L.; Juhas, P.; Liu, J.W.; Bryndin, D.; Božin, E.S.; Bloch, J.; Proffen, T.; Billinge, S.J.L. PDFfit2 and PDFgui: Computer Programs for Studying Nanostructure in Crystals. J. Phys. Condens. Matter 2007, 19, 335219. [CrossRef] [PubMed] 
27. Rodríguez-Carvajal, J. Recent Advances in Magnetic Structure Determination by Neutron Powder Diffraction. Phys. B Condens. Matter 1993, 192, 55-69. [CrossRef]

28. Zlotea, C.; Chevalier-Cesar, C.; Leonel, E.; Leroy, E.; Cuevas, F.; Dibandjo, P.; Vix-Guterl, C.; Martens, T.; Latroche, M. Synthesis of Small Metallic Mg-Based Nanoparticles Confined in Porous Carbon Materials for Hydrogen Sorption. Faraday Discuss. 2011, 151, 117-131. [CrossRef]

29. Aylward, G.; Findlay, T. SI Chemical Data, Third Edition. J. Chem. Educ. 1995, 72, A109. [CrossRef]

30. Akiba, E.; Okada, M. Metallic Hydrides III: Body-Centered-Cubic Solid-Solution Alloys. MRS Bull. 2002, 27, 699-703. [CrossRef]

31. Zepon, G.; Silva, B.H.; Zlotea, C.; Botta, W.J.; Champion, Y. Thermodynamic Modelling of Hydrogen-Multicomponent Alloy Systems: Calculating Pressure-Composition-Temperature Diagrams. Acta Mater. 2021, 215, 117070. [CrossRef]

32. Abe, J.O.; Popoola, A.P.I.; Ajenifuja, E.; Popoola, O.M. Hydrogen energy, economy and storage: Review and recommendation. Int. J. Hydrogen Energy 2019, 44, 15072-15086.

33. Tong, C.-J.; Chen, M.-R.; Yeh, J.-W.; Lin, S.-J.; Chen, S.-K.; Shun, T.-T.; Chang, S.-Y. Mechanical Performance of the Al x CoCrCuFeNi High-Entropy Alloy System with Multiprincipal Elements. Metall. Mater. Trans. A 2005, 36, 1263-1271. [CrossRef]

34. Nygård, M.M.; Sławiński, W.A.; Ek, G.; Sørby, M.H.; Sahlberg, M.; Keen, D.A.; Hauback, B.C. Local Order in High-Entropy Alloys and Associated Deuterides-a Total Scattering and Reverse Monte Carlo Study. Acta Mater. 2020, 199, 504-513. [CrossRef]

35. King, D.J.M.; Cheung, S.T.Y.; Humphry-Baker, S.A.; Parkin, C.; Couet, A.; Cortie, M.B.; Lumpkin, G.R.; Middleburgh, S.C.; Knowles, A.J. High Temperature, Low Neutron Cross-Section High-Entropy Alloys in the Nb-Ti-V-Zr System. Acta Mater. 2019, 166, 435-446. [CrossRef]

36. Shen, C.-C.; Li, H.-C. Cyclic Hydrogenation Stability of $\gamma$-Hydrides for Ti25V35Cr40 Alloys Doped with Carbon. J. Alloys Compd. 2015, 648, 534-539. [CrossRef]

37. Shen, C.-C.; Perng, T.-P. On the Cyclic Hydrogenation Stability of an Lm(NiAl)5-Based Alloy with Different Hydrogen Loadings. J. Alloys Compd. 2005, 392, 187-191. [CrossRef] 